\title{
Identification of a Mutation in the Coding Sequence of the Human Thyroid Peroxidase Gene Causing Congenital Goiter
}

\author{
Marc J. Abramowicz, * Héctor M. Targovnik, ** Viviana Varela, ${ }^{\star}$ Pascale Cochaux, ${ }^{3}$ Leon Krawiec," Mario A. Pisarev," \\ Francisco V. E. Propato, ${ }^{\star}$ Guillermo Juvenal," Hugo A. Chester," and Gilbert Vassart* \\ *Institut de Recherche Interdisciplinaire en Biologie Humaine et Nucléaire, Free University of Brussels, 1070 Brussels, Belgium; \\ ‡Catédra de Genética y Biologia Molecular, Facultad de Farmacia y Bioquimica, Universidad de Buenos Aires, 1113 Buenos Aires, \\ Argentina; "Division Bioquimica Nuclear, Gerencia de Aplicaciones, Comission Nacional de Energia Atomica, \\ 1429 Buenos Aires, Argentina; and ${ }^{\S}$ Service de Génétique, Hôpital Erasme, 1070 Brussels, Belgium
}

\begin{abstract}
Thyroid peroxidase (TPO) is the key enzyme in the synthesis of thyroid hormones, and the TPO defects are believed to be the most prevalent causes of the inborn errors of thyroid metabolism. We investigated an adopted boy with iodide organification defect, who presented with florid hypothyroidism at the age of 4 mo, poorly complied with thyroxine treatment, and developed a compressive goiter necessitating partial resection at the age of 12 yr.

Biochemical studies revealed the absence of TPO activity in the resected tissue. Genomic DNA studies identified a 4 basepair insertion in the eighth exon of the TPO gene, and showed that the patient was homozygous for this frameshift mutation. The direct genetic diagnosis of this mutation can be made by digestion of polymerase chain reaction products with NaeI restriction enzyme. This will help assessing its prevalence among the heterogenous genetic group of TPO defects. (J. Clin. Invest. 1992. 90:1200-1204.) Key words: alternative splicing • inborn errors of metabolism • molecular diagnosis • organification defect • thyroid hormone biosynthesis
\end{abstract}

\section{Introduction}

Congenital hypothyroidism is a public health concern affecting $1 / 4,000$ births. Although most cases result from dysembryogenesis of the thyroid gland, an interesting minority are due to inborn errors of thyroid hormones metabolism ( 1 ). Congenital goiters due to defective synthesis of thyroid prohormone thyroglobulin (TG) ${ }^{1}$ have been investigated in man and in animal models (1-4), and a pathogenic mutation has recently been identified in the human (5); however, the most prevalent cause of inherited defects in thyroid metabolism is believed to be the thyroid peroxidase (TPO) deficiency (6).

TPO is the key enzyme in thyroid hormones formation; it catalyzes both the iodination and the coupling of hormonogenic tyrosyl residues of TG $(7,8)$. TPO is a $110-\mathrm{kD}$ glycopro-

M. J. Abramowicz and H. M. Targovnik contributed equally to the study.

Address reprint requests to Dr. Abramowicz, IRIBHN, Campus Erasme bat C, 808 Route de Lennik, 1070 Brussels, Belgium.

Received for publication 12 February 1992 and in revised form 4 May 1992.

1. Abbreviations used in this paper: TG, thyroglobulin; TPO, thyroid peroxidase.

J. Clin. Invest.

(c) The American Society for Clinical Investigation, Inc.

$0021-9738 / 92 / 10 / 1200 / 05 \$ 2.00$

Volume 90, October 1992, 1200-1204 tein, using heme as a cofactor, whose primary structure has been deduced from the sequence of the cloned complementary DNA (cDNA) (9-11). Sequences involved in the enzymatic mechanism have been postulated by comparison with related peroxidase enzymes (12). The TPO gene, located on chromosome 2 [2pter-2p24] $(10,13)$ consists of 17 exons and 16 introns (14).

Congenital TPO defects, typically transmitted as autosomal recessive traits, result in hypothyroid goiters with failure to convert iodide into organic iodine (organification defect) (8). Genetic heterogeneity is expected in this syndrome, as it may result from several mechanisms (1), including total absence of TPO activity, inability of TPO to bind to the heme cofactor (15), inability to interact with the TG substrate, and abnormal subcellular localization (8). Recent linkage studies supported heterogeneity of the mutations involved, and suggested that one pathogenic TPO mutation might consist of a not yet identified partial genomic deletion (6).

In the present study, we have identified a human mutation causing TPO deficiency. It consists of a duplication of a tetranucleotide -GGCC- in exon 8 of the TPO gene occurring in a homozygous subject presenting with congenital goiter and hypothyroidism. The resulting frameshift generates stop codons in exon 9, which would result in a grossly truncated protein with no expected activity.

\section{Methods}

Patient. D.M., a 4-mo-old adopted male, was referred to the endocrine service (Centro de Investigationes Endocrinologicas, CONICET, Hospital de niños "Ricardo Gutierrez," Buenos Aires, Argentina), where a diagnosis of hypothyroidism was made. The serum thyroxine $\left(T_{4}\right)$ level was $0.1 \mu \mathrm{g} / \mathrm{dl}$ (normal, 5-13 $\mu \mathrm{g} / \mathrm{dl}$ ) and the patient was immediately given thyroid hormone therapy. At the age of $5 \mathrm{yr}$ the physical examination showed moderate to severe mental retardation with speech difficulties and stunted growth. The medication was discontinued and laboratory testing revealed: low serum triiodothyronine $\left(\mathrm{T}_{3}\right)$ $(25 \mathrm{ng} / \mathrm{dl}$, normal $100-200 \mathrm{ng} / \mathrm{ml})$ and $\mathrm{T}_{4}(1.6 \mu \mathrm{g} / \mathrm{dl})$, elevated thyrotropin $(>80 \mu \mathrm{U} / \mathrm{ml}$, normal $<9 \mu \mathrm{U} / \mathrm{ml})$ and a positive thiocyanate discharge test $(27 \%$ discharge of labeled iodine, normal $<10 \%)$. No informations are available regarding compliance of the patient with his treatment. The subsequent evaluation at the age of $10 \mathrm{yr}$ showed: serum $\mathrm{T}_{4}, 0.5 \mu \mathrm{g} / \mathrm{dl}$; serum $\mathrm{T}_{3}, 27 \mathrm{ng} / \mathrm{dl}^{1}{ }^{131} \mathrm{I}$-thyroid uptake was $20 \%$ at 2 and $24 \mathrm{~h}$ (normal, $30-60 \%$ at $2 \mathrm{~h}$ and $15-55 \%$ at $24 \mathrm{~h}$ ) and the thyroid scan revealed a pattern of diffuse goiter. Microsomal antibodies were absent. Thyroidectomy was performed at the age of $12 \mathrm{yr} 9 \mathrm{mo}$ because of compressive symptoms, and the patient was subsequently treated with appropriate thyroid hormone replacement therapy. Histological examination disclosed a multinodular goiter. The follicular epithelial cells showed hyperplasia with papillary projections in the cystic follicles.

Biochemical and molecular genetics techniques. All molecular genetics manipulations involved standard procedures (16). Standard 
precautions were taken to avoid polymerase chain reaction (PCR) contaminations.

The presence of TG in the thyroid tissue from patient DM was investigated by agarose gel electrophoresis (in denatured and reduced conditions), gel filtration on Sephacryl S-300 column, and immunoelectrophoresis. TPO activity was measured by the tyrosine iodinase assay (17). Organification of ${ }^{131} \mathrm{I}$ (given as a $25-\mu \mathrm{Ci}$ tracer dose before surgery) was studied by Sephadex G-200 elution pattern of thyroid homogenate. RNA and DNA samples were prepared from goiter tissue frozen in liquid nitrogen at the time of surgery. Genomic DNA from control subjects was extracted from circulating leukocytes. The goiter genomic DNA from patient D.M. was analyzed by Southern blotting using BglII, EcoRI, PstI, and PvuII restriction enzymes and the TG cDNA probe pbTgM3 (18).

Amplification of overlapping portions of the goiter TG messenger RNA (mRNA), encompassing the whole length of the mRNA, was performed by reverse transcription of total goiter RNA aliquots followed by PCR amplification exactly as described in Ieri et al. (5). By using the same method, couples of primers were designed to amplify the [6-1066], [744-1703], [1524-2400], and [2221-3024] segments of the 3-kb TPO cDNA (19). To facilitate cloning, a couple of nested PCR primers containing restriction sites in 5 ' overhangs, were used to reamplify the 1019-1558 segment from the [744-1703] fragment (forward primer complementary to exon 8 (1019F): 5'tagaattccaccgtgtatggcagctc3'; reverse primer complementary to exon 9 (1558R): $5^{\prime}$ tggaagcttgcgtccagectcctcacc $3^{\prime}$ ). Standard PCR conditions were the following: $1 \mathrm{~min}$ at $93^{\circ} \mathrm{C}, 2 \mathrm{~min}$ at $55^{\circ} \mathrm{C}, 3 \mathrm{~min}$ at $72^{\circ} \mathrm{C}, \times 35$ cycles, in $100-\mu l$ reaction volumes with $1.5 \mathrm{mM} \mathrm{MgCl}_{2}$ and $10 \%$ DMSO. The PCR product was visualized by electrophoresis in a $2 \%$ agarose gel followed by ethidium bromide staining, and aliquots were cloned in M13 mp18 and mp19 and sequenced on both strands (model 370A DNA sequencer, Applied Biosystems, Inc., Foster City, CA).

A 460-bp genomic DNA fragment containing the exon 8 /intron 8 junction was amplified under identical conditions from goiter DNA using the same forward primer complementary to exon $8(1019 \mathrm{~F})$ and a reverse primer complementary to intron 8 (IN8R:5'ataagcttggagagagaagccacgatgc $3^{\prime}$ ). Digestion of the PCR product with SstII (Bethesda Research Laboratories, Gaithersburg, MD) or NaeI (Boehringer Mannheim GmbH, Mannheim, FRG) was performed as described by the manufacturers. NaeI recognizes the sequence 5'GCCGGC 3'. The PCR product was extracted with phenol, $\mathrm{CHCl}_{3}$, then ethanol-precipitated before digestion, and stained with ethidium bromide after electrophoresis in a 3\% agarose gel. Aliquots were cloned in M13 and sequenced on both strands. Additional amplifications were performed using IN8R and a more 5' exonic forward primer (951F:5'ttgaattctttgggaacctgtccacg3'); SstII and Nael digestion, as well as M13 sequencing of this PCR product yielded the same results. A 350-bp fragment containing the intron 8 /exon 9 junction was amplified using a forward primer complementary to the 3 ' region of intron 8 (IN8F:5'tagaattcgcaagaaggcattctgg $\left.3^{\prime}\right)$ and the reverse primer complementary to exon 9 (1558R). The PCR product was cloned in M13 and sequenced on both strands. An additional amplification product spanning the intron 8/exon 9 junction was obtained using $1558 \mathrm{R}$ and a more $3^{\prime}$ intronic forward primer (IN8Fd:5'atgaattcgaggcgaccctcctctgg 3'); it was cloned in M13 and sequenced on both strands, and yielded the same results.

\section{Results}

Organification defect and normal expression of the TG gene. Southern blotting analysis of the TG locus in patient D.M. showed a normal band pattern. Similarly, all fragments of the goiter TG mRNA displayed normal sizes after reverse transcription and PCR analysis (see Methods). The protein was detected in the tissue by agarose gel electrophoresis, gel filtration assay, and immunoelectrophoresis; those three tests showed a normal size of the TG protein (data not shown).
Consistent with the preoperative thiocyanate discharge test indicative of an iodide organification defect, TPO activity in the resected goiter tissue was very low as measured by the tyrosine iodinase assay ( $19 \mathrm{U}$, with $323 \mathrm{U}$ in a control from a patient with multinodular goiter (17), and the sephadex G-200 elution pattern of labeled thyroid proteins showed concentration of ${ }^{131} I$ in the free iodine peak, with no detectable iodination of highmolecular-weight proteins eluted from the column.

Deletion in goiter TPO $m R N A$. By using the same methodology as for TG, PCR amplification of four overlapping segments of the reverse-transcribed goiter TPO mRNA ( see Methods), each $\pm 1 \mathrm{~kb}$ in length, identified $\mathrm{a} \pm 100$-bp deletion in the 1000-1550 region of the normal TPO cDNA; Fig. 1, lane 3, shows the size of this deleted segment $(420 \mathrm{bp})$ as compared with a control from normal thyroid RNA (540 bp, lane 2), where a fainter 420-bp band is also observed; this 420-bp band is not observed in the amplification product from a normal TPO cDNA molecule cloned in a plasmid vector shown in lane 1. A smaller PCR product observed in the goiter is also found in the background of amplification generated in the absence of DNA template $\left(\mathrm{H}_{2} \mathrm{O}\right.$ control, lane 4$)$. The 420-bp segment from the goiter was cloned and sequenced. The deleted sequence (see below) corresponds to the first 124 bp of exon 9, i.e., fragment [1379-1502] of the normal ( $3 \mathrm{~kb}$ ) TPO mRNA $(10,19)$.

Inspection of the goiter TPO cDNA sequence upstream of the deletion readily identified a 4-bp insertion at position 1227 in exon 8, due to the duplication of a GGCC tetranucleotide. By its expected deleterious effect, this frameshift mutation must be considered responsible for the phenotype.

Homozygous mutation in goiter genomic DNA. In order to confirm the presence of the insertion in genomic DNA and to determine whether the patient was homozygous for the mutation, the corresponding region of genomic DNA was amplified, cloned, and sequenced. Duplication of the GGCC tetranucleotide was identified in exon 8 of the TPO gene, 152 bp upstream from the junction with intron 8 (Fig. $2 A$ ). In addition, two point mutations were found by comparison with published sequences $(10,11,14,19)$ (Fig. $2 A$; coordinates as in reference 19). All sequences from the total PCR product showed identical mutations (five clones sequenced). Homozygosity was further demonstrated by the complete digestion of the uncloned PCR product with NaeI (Fig. $2 B$ ). This enzyme recognizes specifically the mutated sequence. The specificity of the major PCR amplification product is indicated by the SstII digestion that generates the expected restriction bands. Also shown in Fig. $2 A$, is the absence of mutation in the region spanning the $3^{\prime}$ splice site of intron 8 . This region was investigated in search

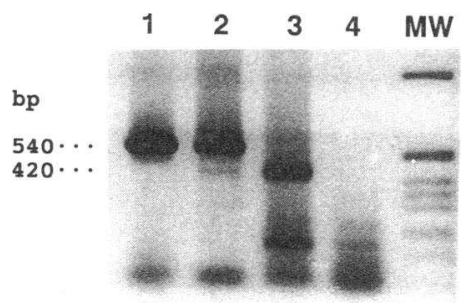

Figure 1. Deletion in goiter TPO mRNA. Ethidium bromide staining of the PCR product of the [10191558 ] region of TPO cDNA amplified from: normal TPO cDNA template cloned in $\mathrm{pBS}$ plasmid (lane 1 ); reverse-transcribed thyroid RNA from a normal control subject

(lane 2); reverse-transcribed goiter RNA from patient DM (lane 3); and $\mathrm{H}_{2} \mathrm{O}$ control (lane 4). $\mathrm{MW}$, molecular size markers ( $\mathrm{kb}$ ladder, Bethesda Research Laboratories). 
A

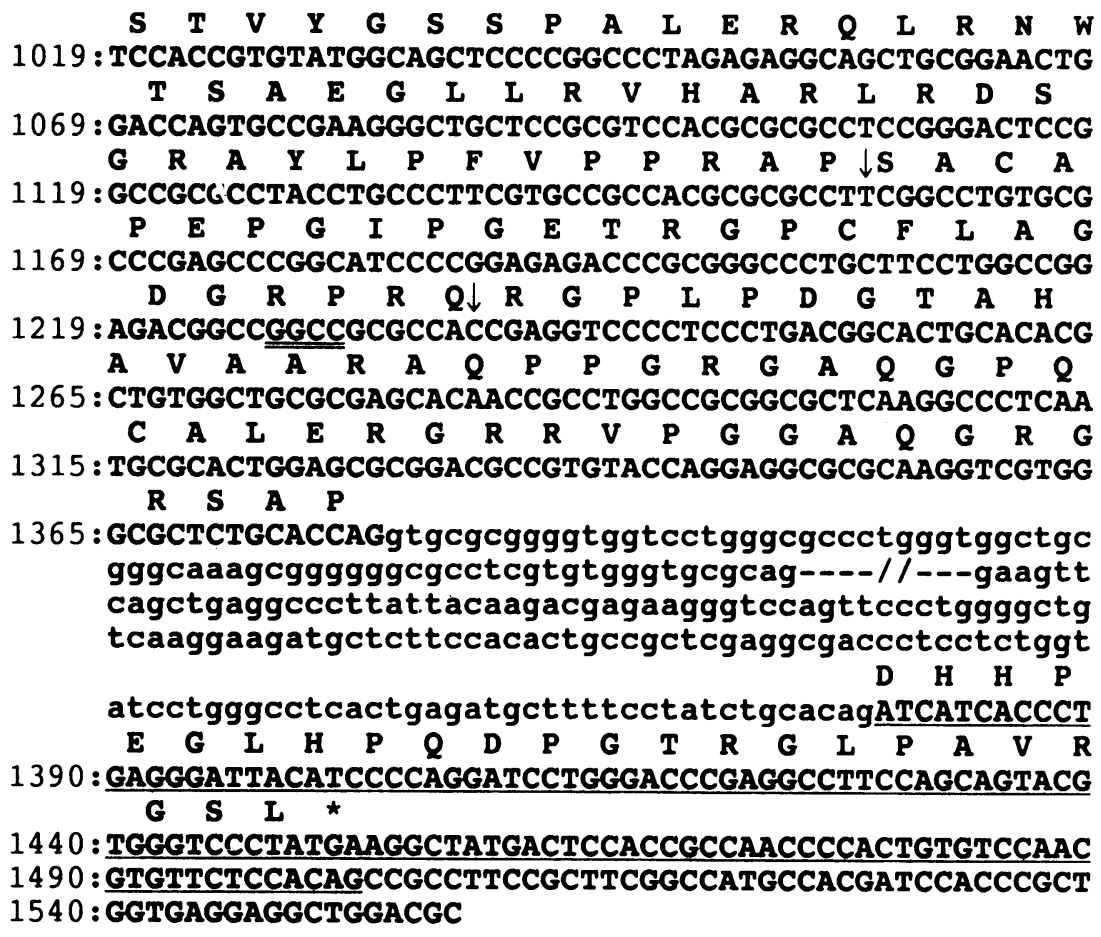

1365 : GCGCTCTGCACCAGgtgcgcggggtggtcctgggegccetgggtggetgc gggcaaagcggggggcgcetcgtgtgggtgcgcag----1/---gaagtt cagctgaggccettat tacaagacgagaagggtccagttccetggggetg tcaaggaagatgctcttccacactgccgctcgaggcgaccctcctctggt

atcctgggcetcactgagatgcttttcctatctgcacagATCATCACCCT

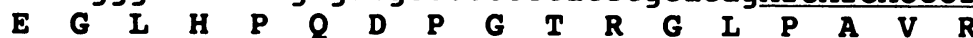
$1390: \frac{\text { GAGGGATTACATCCCCAGGATCCTGGGACCCGAGGCCTTCCAGCAGTACG }}{\text { G S I }}$ 1440 : TGGGTCCCTATGAAGGCTATGACTCCACCGCCAACCCCACTGTGTCCAAC 1490 : GTGTTCTCCACAGCCGCCTTCCGCTTCGGCCATGCCACGATCCACCCGCT 1540 : GGTGAGGAGGCTGGACGC

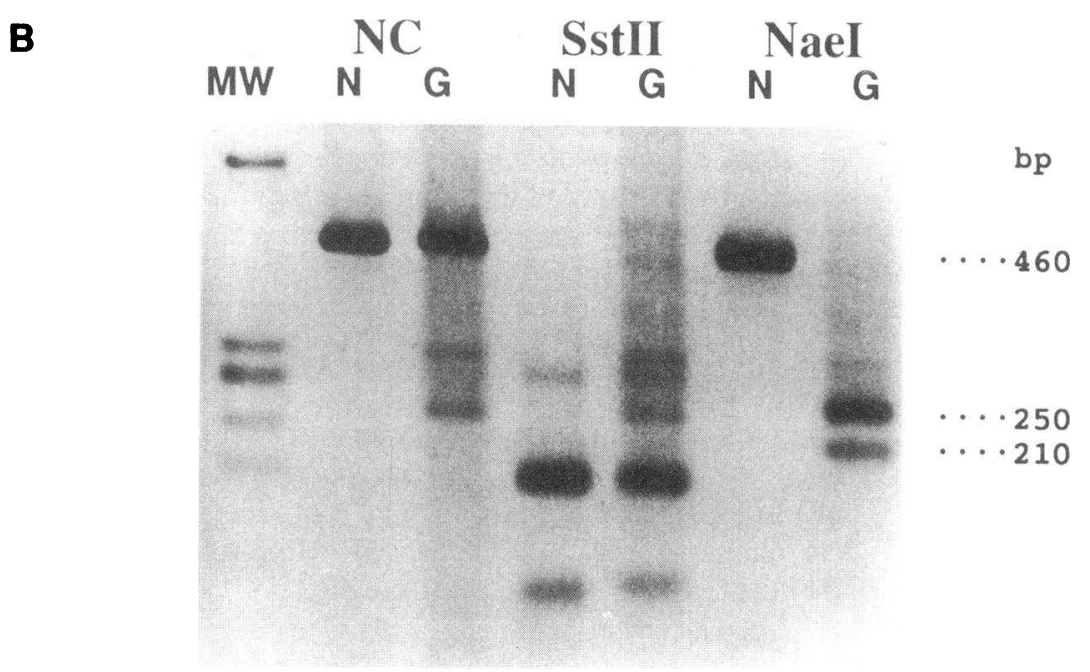

Figure 2. Homozygous mutation in goiter genomic DNA. (A) Partial sequence of the goiter TPO gene exon 8 , intron 8 (lower case letters), and exon 9. The duplicated tetranucleotide is DOUBLE-UNDERLINED. The 124-bp deleted from goiter TPO messenger RNA are underlined. Deduced protein sequence is shown in the one letter code, assuming normal splicing of the transcript. Coordinates refer to the normal cDNA sequence (reference 19). The vertical arrows indicate the point mutations. *First in-frame stop codon. $(B)$ Ethidium bromide staining of a 460-bp genomic DNA fragment encompassing the exon 8 /intron 8 junction, and corresponding to the $5^{\prime}$ part of the sequence described in panel A (from position 1019 in exon 8 through the interruption in intron 8 ), PCR-amplified from normal $(N)$ or goiter $(G)$ genomic DNA and digested as indicated by restriction enzymes SstII or NaeI, which cleaves only if the GGCC duplication is present. NC, not cleaved. MW, molecular size markers (HaeIII fragments of $\varnothing \times 174)$. of a mutation causing a splicing error (e.g., a mutation affecting the $3^{\prime}$ acceptor splice site in intron 8 ) that could have explained the alternative splicing (20).

Fig. 3 shows the expected effects of the mutation and of alternative splicing on the primary structure of the TPO protein. Normal splicing of the mutated transcript would generate a polypeptide less than half the length of normal TPO, with mutation of the proximal-and deletion of the distal-putative heme-binding histidine residues (12). Interestingly, alternative splicing as observed in the goiter TPO mRNA restores the normal reading frame. The result is a nearly full-length protein with a 91-amino acid segment at position [397-487] replaced by a 51-residue unrelated segment which is read in a different frame. This translation product is expected to have an unchanged distal putative heme-binding His, but to lack the proximal putative heme-binding His.

\section{Discussion}

To the best of our knowledge, the GGCC duplication we describe in this study represents the first description of a human TPO mutation resulting in congenital goiter. Homozygosity is consistent with a recessive trait, and a near absence of TPO activity results in iodide organification defect, primary hypothyroidism, and elevated thyrotropin.

Interestingly, besides abolishing the enzymatic activity by disrupting the reading frame of the messenger RNA and introducing stop codons, the GGCC duplication also unmasks a cryptic acceptor splice site in exon 9 . Consistent with cryptic splice site activation, the $3^{\prime}$ extremity of the mRNA deletion contains a short pyrimidine tract and ends with AG (ttctccacag, see Fig. $2 A$ ); it thus fits the acceptor splice site consensus (21). The presence in the normal thyroid control of a small 


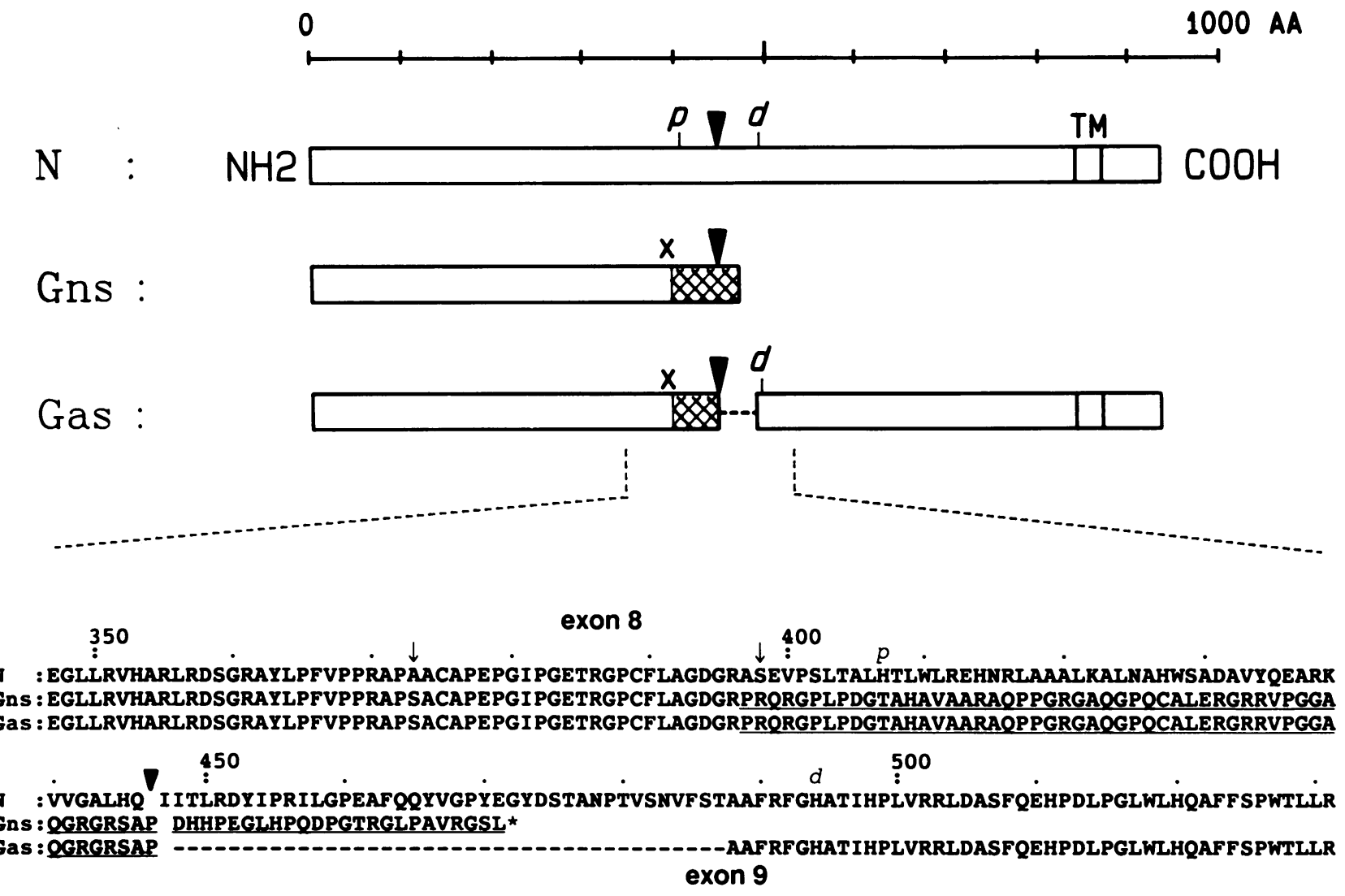

Figure 3. Effects of mutations and splicing on TPO protein sequence. Primary structures of the proteins deduced from cDNA sequences are compared. N, normal gene product; Gns, product of goiter gene and normal splicing; Gas, product of goiter gene and alternative splicing as observed in goiter mRNA from patient DM. $p$ and $d$, putative proximal and distal heme-binding histidine residues, respectively. TM, transmembrane domain. X, GGCC duplication. *Stop codon. Amino acids are in the one-letter code. The mutated region is cross-hatched in the upper panel and underlined in the lower panel. Arrows indicate the point mutations. The arrowhead indicates the exon $8 /$ exon 9 junction. The dashed line denotes deleted amino acids.

amount of PCR-amplified transcript displaying the same size as the goiter transcript (Fig. 1, lane 2) suggests that alternative splicing in the goiter might represent the exacerbation of a naturally occurring phenomenon. Although deleterious in the normal allele, in the mutated allele bearing the GGCC duplication, the alternative splicing might represent a "salvage" mechanism because it restores the normal reading frame disrupted by the mutation and eliminates the stop codons which would truncate the protein in its carboxy-terminal half. Although the physiological relevance of the alternative splicing remains to be elucidated in the case of this study, it is reminiscent of a similar situation described in an animal model of euthyroid congenital goiter with TG defect (22), and of mutations of Becker muscular dystrophy (23). Although no enzymatic activity can be expected from the normal splicing product of the mutated gene (see Results and Fig. 3), the product of alternative splicing of the mutated gene as observed in the goiter mRNA might have some residual TPO activity in spite of mutation of the proximal putative heme-binding $\mathrm{His}$, as other His residues in the peptide might possibly function in heme binding. This could account for the very low residual TPO activity observed in the goiter ( $5 \%$ of a normal control).

In the absence of results from Northern blots of TPO transcripts (due to limitation of tissue availability), it is difficult to estimate the amount of alternatively spliced transcripts in the goiter as compared to the normal message present in control tissue. Absence of amplification of normal-sized TPO cDNA from the goiter is likely to result from destabilization of the mRNA bearing stop codons in the middle of the coding sequence (24).

As no other observations of naturally occurring TPO gene mutation have been reported, it is difficult to speculate on the nature of the additional point mutations found in our patient. They may have accumulated because of lack of selective pressure on the abnormal gene. Alternatively, although they induce a change in amino acids $(1157: \mathrm{G} \rightarrow \mathrm{T}: \mathrm{Ala} \rightarrow$ Ser and 1237:G $\rightarrow \mathrm{C}: \mathrm{Ser} \rightarrow \mathrm{Thr}$ in the reading frame of the normal allele) they may represent polymorphisms that were present before the GGCC duplication; these point mutations are however not found in any of the four independently published sequences $(10,11,14,19)$.

From a practical viewpoint, the presence of the NaeI site in the TPO alleles amplified by PCR as described in Methods provides a rapid test for direct genetic diagnosis of this mutation. Considering the expected genetic heterogeneity of organification defects, analysis of further cases will provide new insight on the structure-function relationships of thyroid peroxidase.

\section{Acknowledgments}

This work was supported by grants from the Fonds de la Recherche Scientifique Médicale, and the Belgian Ministère de la Politique Scien- 
tifique and the Loterie Nationale. Dr. Abramowicz is a Research Assistant at the Fonds National de la Recherche Scientifique, Belgium. Drs. Targovnik, Krawiec, and Pisarev are established investigators of the Argentine National Research Council (CONICET) and Dr. Targovnik was a visiting investigator at the Institut de Recherche Interdisciplinaire en Biologie Humaine et Nucléaire, from 2 April to 2 June 1991, supported by a grant from the United Nations Educational, Scientific and Cultural Organization (UNESCO) and the Third World Academy of Sciences (TWAS). This text presents research results of the Belgian Programme on Inter-University Poles of Attraction, initiated by the Belgian State, Prime Minister's Office, Science Policy programming. The scientific responsibility is assumed by the authors.

\section{References}

1. Dumont, J. E., G. Vassart, and S. Refetoff. 1989. Thyroid disorders. In The Metabolic Basis of Inherited Diseases. 6th edition. C. R. Scriver, A. L. Beaudet, W. S. Sly, and D. Valle, editors. McGraw-Hill, Inc., New York. 1843-1851.

2. Lissitzky, S., J. Bismuth, J. Codaccioni, and G. Cartazou. 1968. Congenital goitre with iodoalbumin replacing thyroglobulin. J. Clin. Endo. Metab. 28:17971803.

3. Taylor, B. A., and L. Rowle. 1987. The congenital goitre mutation is linked to the thyroglobulin gene in the mouse. Proc. Natl. Acad. Sci. USA. 84:19861990.

4. Sterk, A., J. E. Van dijk, G. J. M. Vennboer, A. F. M. Moorman, and J. J. M. De Vijlder. 1989. Normal-sized thyroglobulin mRNA in Dutch goats with thyroglobulin synthesis defect is translated into a 35.000 molecular weight N-terminal fragment. Endocrinology. 124:477-483.

5. Ieri, T., P. Cochaux, H. M. Targovnik, M. Suzuki, S-I. Shimoda, J. Perret, and G. Vassart. 1991. A 3' splice site mutation in the thyroglobulin gene responsible for congenital goiter with hypothyroidism. J. Clin. Invest. 88:1901-1905.

6. Mangklabruks, A., A.-E. Correa Billerbeck, B. Wajchenberg, M. Knobel, N. J. Cox, L. J. De Groot, and G. A. Medeiros-Neto. 1991. Genetic linkage studies of thyroid peroxidase (TPO) gene in families with TPO deficiency. $J$. Clin. Endocr. Metab. 72:471-476.

7. Taurog, A. 1986. Hormone synthesis: thyroid iodine metabolism. In Werner's The Thyroid. S. Ingbar and L. Braverman, editors. J. P. Lippincott Co., Philadelphia. 53-97.

8. Nunez, J., and J. Pommier. 1982. Formation of thyroid hormones. Vitam Horm. 39:175-229.

9. Libert, F., J. Ruel, M. Ludgate, S. Swillens, N. Alexander, G. Vassart, and C. Dinsart. 1987. Thyroperoxidase, an auto-antigen with a mosaic structure made of nuclear and mitochondrial gene modules. EMBO (Eur. Mol. Biol. Organ.) J. 6:4193-4196.
10. Kimura, S., T. Kotani, O. W. Mc Bride, K. Umeki, K. Hirai, T. Nakayama, and S. Ohtaki. 1987. Human thyroid peroxidase: complete cDNA and protein sequence, chromosome mapping, and identification of two alternately spliced mRNA. Proc. Natl. Acad. Sci. USA. 84:5555-5559.

11. Seto, P., H. Hirayu, R. P. Magnusson, J. Gestautas, L. Portmann, L. J. DeGroot, and B. Rapoport. 1987. Isolation of a complementary DNA clone for thyroid microsomal antigen. Homology with the gene for thyroid peroxidase. $J$. Clin. Invest. 80:1205-1208.

12. Kimura, S., and M. Ikeda-Saito. 1988. Human myeloperoxidase and thyroid peroxidase, two enzymes with separate and distinct physiological functions, are evolutionary members of the same gene family. Proteins. 3:113-120.

13. de Vijlder, J. J. M., C. Dinsart, F. Libert, A. Geurts van Kessel, H. Bikker, P. A. Bolhuis, and G. Vassart. 1988. Regional localization of the gene for thyroid peroxidase to chromosome 2pter $\rightarrow$ p12. Cytogenet. Cell. Genet. 47:170-172.

14. Kimura, S., Y-S. Hong, S. Kotani, and F. Kikkawa. 1989. Structure of the human thyroid peroxidase gene: comparison and relationship to the human myeloperoxidase gene. Biochemistry. 28:4481-4489.

15. Medeiros-Neto, G. A., M. Knobel, K. Yamamoto, H. Cavaliere, and W. Kallas. 1979. Deficient thyroid peroxidase causing organification defect and goitrous hypothyroidism. J. Endocrinol. Invest. 2:353-357.

16. Sambrook, J., E. F. Fritsch, and T. Maniatis. 1989. Molecular Cloning, a Laboratory Manual. Cold Spring Harbor Laboratory, Cold Spring Harbor, NY.

17. Pommier, J., J. Tourniaire, D. Dème, D. Chalendar, H. Bornet, and J. Nunez. 1974. A defective thyroid peroxidase solubilized from a familial goiter with iodine organification defect. J. Clin. Endocrinol. Metab. 39:69-80.

18. Malthiéry, Y., and S. Lissitzky. 1987. Primary structure of human thyroglobulin deduced from the sequence of its 8448-base complementary DNA. Eur. J. Biochem. 165:491-498.

19. Libert, F., J. Ruel, M. Ludgate, S. Swillens, N. Alexander, G. Vassart, and C. Dinsart. 1987. Complete nucleotide sequence of the human thyroperoxidasemicrosomal antigen cDNA. Nucleic Acids Res. 15:6735.

20. Kazazian, H. H., Jr., and C. D. Boehm. 1988. Molecular basis and prenatal diagnosis of $\beta$-thalassemia. Blood. 72:1107-1116.

21. Shapiro, M. B., and P. Senapathy. 1987. RNA splice junctions of different classes of eukaryotes: sequence statistics and functional implications in gene expression. Nucleic Acids Res. 15:7155-7174.

22. Ricketts, M., M. J. Simons, J. Parma, L. Mercken, Q. Dong, and G. Vassart. 1987. A nonsense mutation causes hereditary goitre in the Afrikander cattle and unmasks alternative splicing of thyroglobulin transcripts. Proc. Natl. Acad. Sci. USA. 84:3181-3184.

23. Chelly, J., H. Gilgenkrantz, M. Lambert, G. Hamard, P. Chafey, D. Recan, P. Katz, A. de la Chapelle, M. Koenig, I. B. Ginjaar, et al. 1990. Effect of dystrophin gene deletions on mRNA levels and processing in Duchenne and Becker muscular dystrophies. Cell. 63:1239-1248.

24. Chang, J. C., and Y. W. Kan. 1979. Beta-O thalassemia, a nonsense mutation in man. Proc. Natl. Acad. Sci. USA. 76:2886-2889. 